\title{
Database Security: An Overview and Analysis of Current Trend
}

\author{
P. K. Paul ${ }^{1}$ \& P. S. Aithal ${ }^{2}$ \\ ${ }^{1}$ Executive Director, MCIS, Department of CIS, Raiganj University (RGU), West Bengal, India \\ ${ }^{2}$ Vice Chancellor, Srinivas University, Karnataka, India \\ Email:pkpaul.infotech@gmail.com
}

Area/Section: Computer Science

Type of the Paper: Research Paper.

Type of Review: Peer Reviewed.

Indexed in: OpenAIRE.

DOI: http://doi.org/10.5281/zenodo.3491364.

Google Scholar Citation: IJMTS

\section{How to Cite this Paper:}

Paul, P. K., \& Aithal, P. S. (2019). Database Security: An Overview and Analysis of Current Trend. International Journal of Management, Technology, and Social Sciences (IJMTS), 4(2), 53-58. DOI: http://doi.org/10.5281/zenodo.3491364.

International Journal of Management, Technology, and Social Sciences (IJMTS) A Refereed International Journal of Srinivas University, India.

IFSIJ Journal Impact Factor for $2018=4.764$

(C) With Authors.

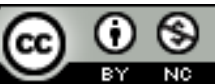

This work is licensed under a Creative Commons Attribution-Non Commercial 4.0 International License subject to proper citation to the publication source of the work.

Disclaimer: The scholarly papers as reviewed and published by the Srinivas Publications (S.P.), India are the views and opinions of their respective authors and are not the views or opinions of the SP. The SP disclaims of any harm or loss caused due to the published content to any party. 


\title{
Database Security: An Overview and Analysis of Current Trend
}

\author{
P. K. Paul ${ }^{1}$ \& P. S. Aithal ${ }^{2}$ \\ ${ }^{1}$ Executive Director, MCIS, Department of CIS, Raiganj University (RGU), West Bengal, India \\ ${ }^{2}$ Vice Chancellor, Srinivas University, Karnataka, India \\ Email:pkpaul.infotech@gmail.com
}

\begin{abstract}
Information is the core and most vital asset these days. The subject which deals with Information is called Information Science. Information Science is responsible for different information related affairs from collection, selection, organization, processing, management and dissemination of information and contents. And for this information related purpose Information Technology plays a leading role. Information Technology has different components viz. Database Technology, Web Technology, Networking Technology, Multimedia Technology and traditional Software Technology. All these technologies are responsible for creating and advancing society. Database Technology is concerned with the Database. It is worthy to note that, Database is concerned with the repository of related data in a container or base. The data, in Database normally stored in different forms and Database Technology play a lead role for dealing with the affairs related to database. The Database is very important in the recent past due to wider applications in different organizations and institutions; not only profit making but also non-profit making. Today most organizations and sectors which deal with sensitive and important data keep them into the database and thus its security becomes an important concern. Large scale database and its security truly depend on different defensive methods. This paper talks about the basics of database including its meaning, characteristics, role etc. with special focus on different security challenges in the database. Moreover, this paper highlights the basics of security management, tools in this regard. Hence different areas of database security have mentioned in this paper in a simple sense.
\end{abstract}

Keywords:Database, Database Technology, Security Technology, IT Management, Information Networking, Privacy and Security Management, Trust Management, Cloud Computing.

\section{INTRODUCTION :}

Database security is a kind of collective measures which is required to protect as well securing the database from dishonest use. Moreover, Database Security protects malicious threats and attacks. Database Security is wide area and includes a multitude of processes, tools as well as methodologies keeps security within a database and allied environment [2], [7].There should be proper tools and way to secure the database and complete storage systems. Today almost all types of organizations and institutions are using IT and there all the date are saved into the database; so proper and adequate database security are very important and required. There are different methods for securing database and among these important are include access control, access authorization etc.

\section{OBJECTIVE AND AGENDA :}

Present paper is theoretical and basic paper and kind of overview regarding Database Security; the following are the core aim and objective of the paper- 
- To know the basic of Database Security including its meaning, nature and characteristics in brief manner.

- To learn about the basics importance and need of Database Security including allied fields of Database Security.

- To learn about the probable situation for the security regarding database.

- To learn about the threat and attack related to the Database Security in brief manner.

- To find out the threat management of Database Security in basic and brief manner.

\section{DATABASE SECURITY: THE ROOT :}

Database security is an important component of IT Security and it is responsible for the protecting database against intentional as well as accidental threats. Database Security is not only applicable to the data resides in an organization's database;moreover, it is breaking the security of other part of the database or allied part and may ultimately affect the overall database structure [1], [3], [8]. It is moreover dedicated to the hardware, software part, human resource, and data safety directly and indirectly. For healthy and sophisticated security, it is essentialthat appropriate controls are ready and provided. database security is needed for managing following cases-

- Theft and fraudulent.

- Loss of confidentiality or secrecy, Data Privacy

- Loss of data integrity.

- Loss of availability of data and content These above-mentioned cases are only basic. And an organization should focus on reducing the risk loss as well as damage to data within a database. As a whole following figure: 1 can depict the areas of Database Security in brief. However apart from the technicalities database may also damage in physical cases and among the reason important are fire in the systems or computer room; or byfloods or by the overheating, static discharge, electronic breakdowns. Moreover, sometime it may cause for the equipment failures etc.

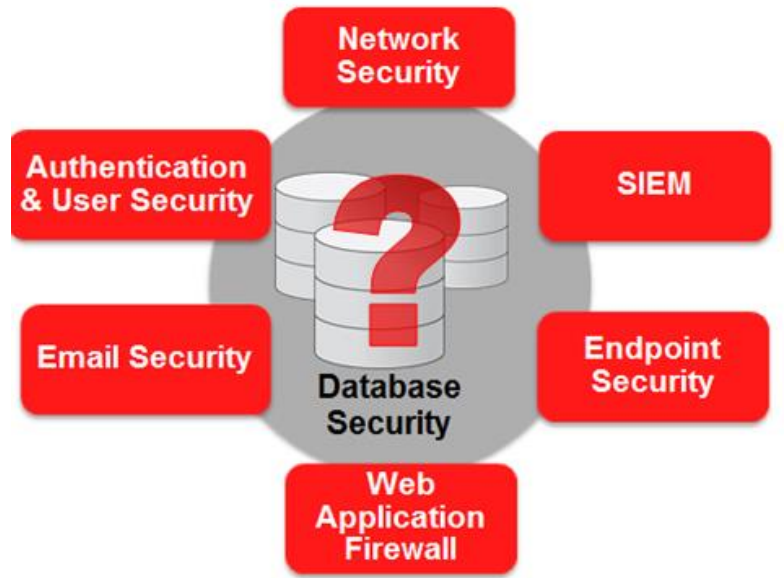

Fig. 1 :Database Security, relationship, and applicability

\section{DATABASE SECURITY: ALLIED CONCEPTS :}

Database security is an important part of Information Technology Security and thus Database security can also be considered as a Cyber Security as well [4], [5]. Database security is one of the subset of IT Security and thus it has very close communication with other areas of security viz.-

- Network Security

- Web Security

- Emerging Cloud Security

- Emerging Mobile Security

- Application Security etc.

Security and its importance is increasing rapidly as all types of organizations and institutions are using Database. The threats and attacks are increasing rapidly and simultaneously defending methods as well.

\section{DATABASE, THREATS, AND ATTACKS :}

Different types of threats on computer systems are there, few are technical and few are from physical. Usually the security of the DBMS can be as follows-

- Access authorization.

- Access controls.

- Backup of data.

- Recovery of data.

- Integrity of Data

- Encryption of data.

- Technology related to the RAID. 
Hence, Database Security is about the protectingthe databases such as data, such as the database applications including the stored functions; and complete database and similar systems.As far as Security is concerned few things are very common viz. Confidentiality, integrity and availability. Database security is affairs should be confirmed and measured by the following-

- Technical

- Procedural/administrative and

- Physical

There are different styles ofprotecting data can vary and increasing rapidly day by day. Among the possible, few important are include (but not limited to) -

- Unauthorized activity by the authorized or unauthorized database users. And the users even may include the database administrators, systems managers, network administrators etc.Access of the hackers to the valuable, confidential and sensitive data [6], [9], [11].

- Unauthorized and similar activities within the databases or various changes in the repository or database data or the database programs including the structures as well as security configurations.

- Malware infections can be done with an unauthorized access as well as leakage of dataproprietary data. Delete data or delete the data or programs. Moreover, sometimes the denial of authorized accessmay act as attacks on database systems and can lead the database failure.

- Overloads including the performance constraints are major database security issue. Moreover, the capacity issues resulting dad governance in database systems.

- Physical damage is another concern which may cause by the fires or floods. Even sometimes it may be based on overheating, lightning. Some expert expressed this as the electronic equipment failures as well.

- Design flaws (including the bugs in programming and simply in the databases programs can result the data loss as well as corruption even it may cause the performance degradation etc.;
- Data corruption due to the entering invalid data and or commands, also mistake in the database can result weakness in database or repository systems. According to the NCC Group Study, UK following are the common database security issues (refer Fig: 2).

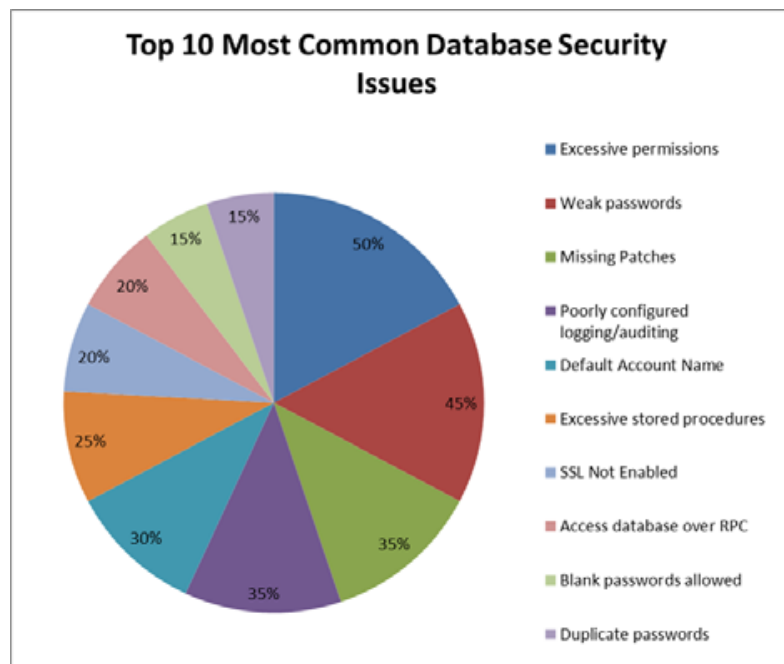

Fig. 2 : Some of the common Database Security Survey (NCC Group Survey, UK)

\section{SECURITY MANAGEMENT \&} DATABASE :

Database Security can be managed by different way and tools and among these few important are include as follows-

- Recovery of the Systems/Database: Database Management System (DBMS) should offer backup facilities having the recovery of the concerned database after, if failed. Backup copies are need to maintain regularly in a perfect location as well.

- Minimizing unauthorized use of the database to the systems by ensuring strong as well as multifactor access including the data management controls

- Load balancing and testing including the capacity testing id important in the database systems to ensure or user overload; it should ensure it is not crashing a DDoS attack.

- Physical security of the systems (i.e. Database) including the server; all types of backup tools, devices and equipment should 
be provided from the safety of natural disasters.

- Monitoring, evaluation of the existing system of the database for the vulnerabilities are important concern [10], [12].

\section{DATABASE SECURITY POLICY :}

Every organizations and institutions this should take proper initiative and policies for the healthy, advanced and secure database system administration. Database administration plays a leading role in securing complete database systems and administration. A DBA is deals critical role in managing the databases of different kind of various organizations. Among the tools used by the database administrators to keep data safe and secure; few important are include-

- Controlling access to the database

- Providing the support services the client or users

- Managing proper strategies backup as well as recovery of data/ contents

- Ensuring data integrity

- Controlling data security

- Setting data privacy

- Formulation of IT Norms and Guidelines [5], [13].

Moreover, the careful controlling access to the data helps in better data security as wellas data privacy.

\section{CONCLUSION :}

Databases and overall systems are normally face a number of security threats. Many of these threats are common in small organizations but in case of big organizations and institutions vulnerability is very importantas they hold sensitive information and different people and section used such. In Data loss, anyparts of a database can no longer be retrieved; so for secure data security it is very important and valuable. Physical damage is an important concern in database securityfrom the fire or water damage, human error or hardware failures etc. The norms and guidelines should be also an important matter for the healthy and sophisticated security practice as far as database systems is concerned.

\section{REFERENCES :}

[1] Borgesius, F. Z., Gray, J., \& Van Eechoud, M. (2015). Open data, privacy, and fair information principles: Towards a balancing framework. Berkeley Technology Law Journal, 30(3), 2073-2131.

[2] Bulgurcu, B., Cavusoglu, H., \& Benbasat, I. (2010). Information security policy compliance: an empirical study of rationalitybased beliefs and information security awareness. MIS quarterly, 34(3), 523-548.

[3] George, B., \& Valeva, A. (2006). A database security course on a shoestring. In $A C M$ SIGCSE Bulletin (Vol. 38, No. 1, pp. 7-11). ACM.

[4] Krishnan, V., McCalley, J. D., Henry, S., \& Issad, S. (2011). Efficient database generation for decision tree based power system security assessment. IEEE Transactions on Power systems, 26(4), 2319-2327.

[5] Li, Y., Stweart, W., Zhu, J., \& Ni, A. (2012). Online privacy policy of the thirty Dow Jones corporations: Compliance with FTC Fair Information Practice Principles and readability assessment. Communications of the IIMA, 12(3), 5.

[6] Mathieu, R. G., \& Khalil, O. (1998). Data quality in the database systems course. Data Quality Journal, 4(1), 1-12.

[7] Murray, M., \& Guimaraes, M. (2008). Expanding the database curriculum. Journal of Computing Sciences in Colleges, 23(3), 6975.

[8] Murray, M. C. (2010). Database security: What students need to know. Journal of information technology education: Innovations in practice, 9, IIP-61.

[9] Neto, A. A., Vieira, M., \& Madeira, H. (2009). An appraisal to assess the security of database configurations. In 2009 Second International Conference on Dependability (pp. 73-80). IEEE.

[10] Said, H. E., Guimaraes, M. A., Maamar, Z., \& Jololian, L. (2009). Database and database 
application security. ACM SIGCSE Bulletin, 41(3), 90-93.

[11] Sandhu, R. S., \& Jajodia, S. (1993). Data and database security and controls. Handbook of information security management, Auerbach Publishers, 1-37.

[12] Smith, G. W. (1991). Modeling securityrelevant data semantics. IEEE Transactions on Software Engineering, (11), 1195-1203.

[13] Srinivasan, S., and Anup Kumar. (2005). Database security curriculum in InfoSec program. In Proceedings of the 2nd annual conference on Information security curriculum development, pp. 79-83. ACM.

$* * * * * * *$ 